
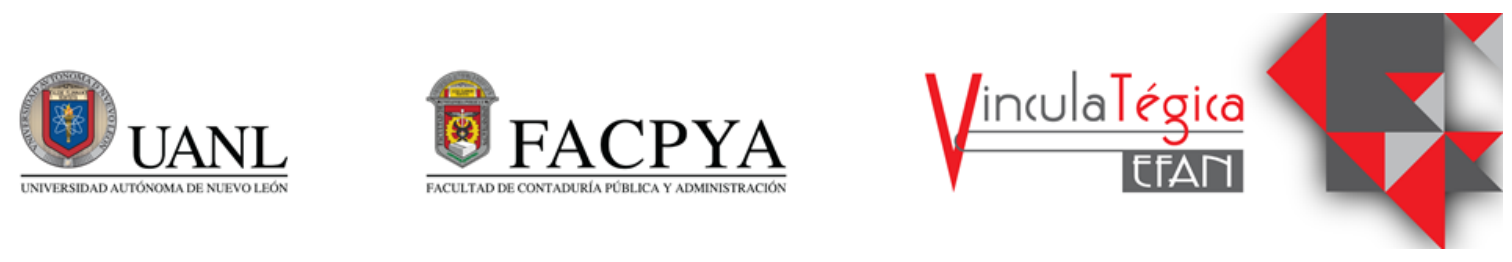

\title{
Efectos del Covid-19 en la industria de la construcción en Monterrey (Nuevo León)
}

\author{
María Priscila Adame Veloz ${ }^{1}$ \\ ${ }^{I}$ Estudiante de Posgrado de la Facultad de Arquitectura en la Universidad Autónoma de Nuevo León, \\ maria.adamevlz@uanl.edu.mx, Pedro de Alba S/N, Niños Héroes, Ciudad Universitaria, San Nicolás de los \\ Garza, N.L, (818)4606382
}

Información del artículo revisado por pares

Fecha de aceptación: junio-2021

Fecha de publicación en línea: diciembre-2021

DOI: https://doi.org/10.29105/vtga7.1-120

\section{Resumen}

La llegada de la crisis sanitaria, cambio de forma radical el desarrollo y actividades en Nuevo León, marzo 2020, proveniente de Wuhan en China arribo a México la Covid-19 (coronavirus disease) conocida como nuevo coronavirus, causado por el coronavirus 2 del síndrome respiratorio agudo severo (SARS - Cov2), Diversos sectores esenciales fueron afectados, Sector Agrícola, Servicios Hospitalarios, Manufactura de Artículos Críticos, Automotriz, Aeroespacial y Construcción. Según datos del Instituto Nacional de Geografía y Estadística (INEGI) en el mes de abril se presentó una caída del $22.54 \%$ en el sector constructivo. Se pretende identificar los efectos frente a la pandemia por el Covid-19 presentes en los trabajadores del sector constructivo. Se llevó acabo un muestreo no probabilístico en el cual se aplicó una encuesta a 101 personas para medir y posteriormente para identificar alguna de las sensaciones de Estrés, Ansiedad, Irritabilidad, Cansancio, Soledad, Depresión o Ninguna. Se obtuvo como resultados a partir de los sujetos encuestados en su mayoría un porcentaje de hombres $(55.4 \%)$ respecto a mujeres (44.6\%). Las personas trabajan en Constructora (39.6\%), Diseño (22.8\%), Administración (13.9\%) Empresa Personal (12.9\%) Desarrollo Urbano $(5.1 \%)$, Vivienda en Serie $(4 \%)$. Las sensaciones presentadas a los entrevistados fueron Ninguna (27.7\%), Estrés (24.8\%), Ansiedad (13.9\%), Soledad (11.9\%), Cansancio (7.9\%), Irritabilidad (5.9\%) y Depresión (5.9\%). Frente al combate de la pandemia COVID-19 las personas presentaron en su mayoría

\begin{abstract}
The arrival of the health crisis, radically changed the development and activities in Nuevo León, March 2020, from Wuhan in China, the Covid-19 (coronavirus disease) arrived in Mexico, known as the new coronavirus, caused by the coronavirus 2 syndrome. severe acute respiratory tract (SARS Cov2), Various essential sectors were affected, Agricultural Sector, Hospital Services, Critical Articles Manufacturing, Automotive, Aerospace and Construction. According to data from the National Institute of Geography and Statistics (INEGI), in April there was a drop of $22.54 \%$ in the construction sector. The aim is to identify the effects of the Covid19 pandemic on workers in the construction sector. A non-probability sampling was carried out in which a survey was applied to 101 people to measure and later to identify any of the sensations of Stress, Anxiety, Irritability, Tiredness, Loneliness, Depression or None. The results were obtained from the subjects surveyed, mostly a percentage of men $(55.4 \%)$ compared to women $(44.6 \%)$. People work in Construction (39.6\%), Design (22.8\%), Administration (13.9\%) Personal Company (12.9\%) Urban Development (5.1\%), Serial Housing (4\%). The sensations presented to the interviewees were None (27.7\%), Stress (24.8\%), Anxiety (13.9\%), Loneliness $(11.9 \%)$, Tiredness (7.9\%), Irritability $(5.9 \%)$ and Depression $(5.9 \%)$. Faced with the combat of the Covid-19 pandemic, the majority of people presented no symptoms and followed by high levels of Stress and Anxiety.
\end{abstract}


ningún síntoma y seguido de esto niveles altos de Estrés y Ansiedad.

Palabras clave: covid-19, estrés, Monterrey.

\section{INTRODUCCIÓN}

Un cambio drástico se presentó en el Estado de Nuevo León ante la llegada del COVID-19 una de las crisis sanitarias que más impacto ha tenido en los últimos tiempos. Sectores importantes como lo son Sector Agrícola, Servicios Hospitalarios, Manufactura de

Artículos Críticos, Automotriz, Aeroespacial y Construcción fueron afectados.

Según datos del Instituto Mexicano del Seguro Social (IMSS), en los meses de abril y mayo, la pérdida de empleos fue mayor en el sector de la construcción, ya que se registró la desocupación de 28,000 personas, una cifra no antes vista. Derivado de la crisis sanitaria muchos de nuestros trabajadores de la construcción, experimentaron momentos de verdadera crisis, y derivado de esto se vivió una tensión no solo a nivel estado también a nivel federal. Es por esto que debido a los altos

\section{MARCO TEÓRICO}

Se realizó un muestreo no probabilístico (bola de nieve). Se realizó una encuesta a 101 candidatos atraves de la plataforma Google Formularios en la cual respondieron desde su perspectiva. La información nos ayudará a descubrir la detonante de dichos efectos y nuestro foco principal serán estrés, ansiedad, irritabilidad, cansancio, soledad y depresión ¿Cuál es la causa de los efectos producidos por el confinamiento en la construcción? Sobre la información conocida respecto a alteraciones causadas por el COVID-19 son diversas pero muy puntuales.

El propósito para lograr este estudio será investigar estos factores, mediante el estudio de algunos artículos referentes Arias Molina (mayo 2020), señala que el estrés se deriva de problemas externos que podamos sufrir, o que estemos viviendo, algunos efectos negativos derivados de esto pueden generar (distress), lo que ocasiona problemas en el organismo. El inicio y prolongación de estos estados de ánimo durante su inicio y hasta la
Keywords: Covid-19, stress, Monterrey.

JEL: I31, J01, I1.

índices de mortandad que se presentaron en el estado la mayoría de estos sectores detuvieron sus actividades algunos meses. Lo que ocasiono efectos psicológicos afectando principalmente el estado anímico. ¿Cómo llego?, ¿Cómo se combatió?, ¿Medidas y soluciones?, En el presente estudio se analiza los estragos

sociales y el impacto que todo esto causó, específicamente en el "estrés laboral y depresión”. Sieglin y Tovar (2007) mencionan algunos factores que van desde el tiempo laborado y las actividades que realiza, así como la toma de decisiones y los resultados que repercuten en el nivel de estrés, además de disminuir la capacidad para controlarlos. El siguiente artículo tiene el objetivo de mostrar una época que sorpresivamente impactó y sus efectos.

fecha.

2.1 Caso COVID-19 ¿Cómo llegó a nuestro estado?

El estado actualmente cuenta con 5,784,442, habitantes tan sólo el área metropolitana conforma los siguientes municipios principales y colindantes y en los que se genera la mayor actividad laboral son: Monterrey $(1,109,171)$, San Nicolás de los Garza (430,143), Guadalupe $(682,880)$, Juárez $(333,481)$, Apodaca $(597,207)$, Escobedo (425,148), García (247,370), Santa Catarina $(296,954)$, San Pedro Garza García $(123,156)$ (INEGI, 2015).

El pasado mes de Marzo de 2020 entró al Estado el virus SARS-CoV-2, proveniente Wuhan en China, aparentemente un habitante del municipio de San Pedro Garza García fue el que trajo consigo esta enfermedad según datos de la OMS el virus COVID-19 ya infectó a más de 128 millones de seres humanos, una enfermedad viral la cual hizo un cambio 
radical no solo en la psicología del ser humano sino también en las costumbres y modalidades de trabajar ya que inmediatamente en el estado entró el distanciamiento social medida implementada por el gobierno federal.

$$
\text { Las primeras semanas }
$$

inmediatamente marcaron y señalaron las autoridades no salir de casa y en los sectores obreros y de educación cerraron sus actividades, se mantuvo un tiempo con esas medidas y después por el mes de agosto algunas empresas implementan la modalidad virtual, semipresencial y presencial en casos especiales, un cambio completamente nuevo (marzo 2020) Gobierno del Estado de Nuevo León. el virus COVID-19 dejó a su paso hasta hoy 172, 865 casos confirmados de los cuales hubo 10, 417 defunciones, específicamente el municipio que presentó más infectados fue Monterrey con 47,593 casos, El estado de Nuevo León se caracteriza por ser el pionero en el área Obrera y se mantiene siempre en constante actividad laboral.

\subsection{Caso COVID-19 ¿Cómo} combatió el área constructiva estas medidas y cuál fue el impacto en los trabajadores?

Según datos y publicaciones (mayo 2020) Secretaria de Economía y Trabajo. La formalidad en el estado posiciona a el sector constructivo en la media es decir con una relación de asegurados en él. El municipio de Monterrey el cual cuenta con el mayor número de población 1, 109,171 habitantes mantienen concentrado el mayor número de constructoras, administrativas, de diseño, gestión de proyecto, urbanísticas y de gobierno. Existe un total de 184 empresas dentro del padrón de empresas contratadas en la secretaría. Estas se encuentran registradas, pero además hay otras pequeñas y medianas empresas, incluso negocios propios que no están dentro de este número.

Según la presentación del Gobierno de Nuevo León (mayo 2020) "Plan de Reactivación Económica y Social del Gobierno de Nuevo León, a causa del COVID - 19". Explica una medición de los impactos económicos respecto los índices en altas y bajas de hospitalización a causa de esta enfermedad, desde que se inició la pandemia y hasta la fecha los distintos sectores han mantenido las medidas de salud correspondientes.

Las medidas que se publicaron en marzo 2020 señalaron una estrategia de combate a la propagación del virus y es que en un inicio se estipularon sectores prioritarios como lo fue, sector agrícola, servicios hospitalarios y manufactura de artículos críticos, Los sectores que se incorporaron en el mes de mayo fueron el Automotriz, Aeroespacial y el de la Construcción el cual incluso desde inicios de la pandemia algunas empresas aún ordenaban a sus trabajadores ir a obra u otras actividades, básicamente solo se les pedía usar las medidas de protección: mascarillas y gel y con esto mitigar la presión por la pandemia, en Nuevo León los sectores Industriales y de Construcción son los que más aportan a la economía, es por esto que ante la crisis existencial ejercieron presión para que estos sectores fueran activados de nueva cuenta. Planteando de nueva cuenta la pregunta anterior, cómo ¿Cómo fue el impacto que esto causó en los trabajadores? Como mencionamos anteriormente en el sector constructivo resintieron esta crisis y es que para algunos el estado de ánimo fue un factor preponderante al momento de desempeñar sus actividades.

\subsection{Caso COVID-19 Medidas y soluciones para enfrentarlo}

La mejor manera de enfrentarlo y salir de esta crisis fue el no pensar tanto en cosas negativas, hacer activación física, ejercitando el cuerpo, caminando, en lo mental trabajando en lo que más te apasiona incluso emprender, aprender un nuevo idioma, un nuevo curso, etc. Las opciones son variadas. Ante todo, esto los detonantes principales de la crisis de estrés emocional fue lo económico y los pensamientos absolutos por una crisis sanitaria que podría durar años lo cierto es que existe y 
tendremos que cuidarnos y aprender a vivir con esto.

\section{MÉTODO}

Para poder plantear la medición se usó el muestreo no probabilístico, se realizó una encuesta a 101 personas referente al impacto que el COVID- 19 causó en el sector Constructivo, se tomaron las variables que permitieron dar respuesta a la medición mediante opción múltiple a continuación se desglosan las palabras sintetizadas (variables) derivadas del cuestionario y su descripción.

Nuestro objetivo se basa en desarrollar lo siguiente: Primero abordamos una búsqueda de artículos relacionados con nuestro tema que podría definirse como la investigación descriptiva, recabando datos de otras fuentes, preguntando, observando y reuniendo la mayor información posible para su desarrollo. El propósito de recabar información sobre el COVID-19 es para realizar un reporte sobre las afectaciones que esta enfermedad sanitaria dejó durante el confinamiento y más específicamente en el área constructiva en Monterrey Nuevo León.

Primero investigaremos el comportamiento y las actividades que se plantearon apenas iniciada la pandemia ¿Cómo llegó a nuestro estado?

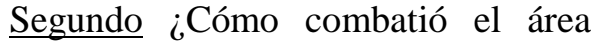
constructiva estas medidas? y ¿Cuál fue el impacto que causó en los trabajadores de la construcción?, para responder esta y otras interrogantes abordaremos el tema con puntos de vista, información recabada y la opinión de otros autores.

Tercero Medidas y soluciones para enfrentarlo.

Modalidad: en el cambio drástico de espacio laboral repercute en el estado de ánimo y las emociones, incluso en la toma de decisiones Yris Yessenia Usma Flórez. (Noviembre 2020), señalaba en su artículo "El estrés laboral y su incremento durante el confinamiento" que las personas en sus días laborales suelen tomar decisiones importantes que afectan al funcionamiento y entorno de trabajo, por esta razón el tener un control de los estados anímicos es importante en las empresas ya sea que cada año se presenten exámenes para medir como te encuentras psicológica y físicamente. La sensación:

Figura 1 "Grafico Sensaciones" como un cambio en tu estado anímico en el mismo artículo Yordany Arias Molina. (Mayo 2020) "Manifestaciones psicológicas frente a la situación epidemiológica causada por el COVID-19" Cuando se vive una situación de peligrosidad o peligroso a futuro la mente y el cuerpo generan una respuesta emocional y psicofísica que prepara al cuerpo para enfrentar alguna crisis a futuro, en el caso de la variable definimos las siguientes emociones: Estrés, Ansiedad, Irritabilidad, Cansancio, Soledad y Depresión.

Desempleo: el cual se incrementó en los primeros meses de pandemia y posterior a ello dejando una afectación en la economía del Estado. Combatir:

figura 4 "Grafico Combatir" La sensación antes mencionada puede ser posible mediante activación física o mental poner a trabajar estas dos partes del cuerpo, según la Organización Mundial de la Salud (OMS) señala que la actividad física puede ser un factor estimulante y de gran ayuda para el manejo de cualquiera de las sensaciones emocionales. 
Los datos seleccionados en la Tabla 1 "Descripción de variables" muestra entre las variables aquellas en las que se obtuvieron los resultados.

Tabla 1. Descripción de variables

\begin{tabular}{|c|c|}
\hline Variable & Definición \\
\hline Edad & $\begin{array}{l}\text { Número de años del encuestado, representado por } \\
\text { número en un rango del } 0 \text { al } 100 .\end{array}$ \\
\hline Género & Selección respuesta hombre $=1$, Mujer $=2$. \\
\hline Civil & $\begin{array}{l}\text { Situación de relación actual de la pareja, en que } \\
\text { condición sentimental se encuentra. }\end{array}$ \\
\hline Educación & $\begin{array}{l}\text { Grado de estudios académicos, hasta que nivel de } \\
\text { aprendizaje ha obtenido. }\end{array}$ \\
\hline Giro & $\begin{array}{l}\text { Actividad de la empresa, cual es el trabajo que realizas y } \\
\text { el más demandante. }\end{array}$ \\
\hline Responsabilidad & $\begin{array}{l}\text { Nivel demandante de actividades, dentro de grado están } \\
\text { tus labores. }\end{array}$ \\
\hline Modalidad & $\begin{array}{l}\text { Forma de trabajo durante la pandemia, que tipo de } \\
\text { contacto tenías con tu entorno laboral. }\end{array}$ \\
\hline Reducción & $\begin{array}{l}\text { Disminución salarial, reducción porcentual respecto al } \\
\text { total del salario recibido. }\end{array}$ \\
\hline Sensaciones & $\begin{array}{l}\text { Experiencia de estado anímico durante confinamiento, } \\
\text { emociones psicológicas y físicas. }\end{array}$ \\
\hline Contagio & $\begin{array}{l}\text { Tuvo contagio durante la pandemia, afirmación o } \\
\text { negación de si se tuvo algún síntoma durante } \\
\text { confinamiento. }\end{array}$ \\
\hline Desempleo & Perdió o emprendió durante la pandemia. \\
\hline Combatir & Medidas que tomo para combatir la pandemia \\
\hline
\end{tabular}

Fuente: Elaboracion propia.

Los resultados obtenidos en la tabla 2 "Caracteristicas encuestados" describe la frecuencia y el porcentaje de las variables Constructora Administración como el giro con

\section{RESULTADOS}

En esta sección se muestran los resultados descriptivos y de frecuencias obtenidos en el levantamiento de la información con los sujetos de estudio, los cuales nos permitirán conocer cuál era la situación en el momento de mayor respuesta de los encuestados descripción en la table 1 "Descripcion de variables."

contactarlos, así como cuantificar si existe un grado de estrés emocional en los trabajadores de la construcción del área metropolitana de Monterrey.

Tabla 2. Características de los encuestados 


\begin{tabular}{|c|c|c|c|}
\hline Variable & & Frecuencia & Porcentaje \\
\hline \multirow[t]{3}{*}{ Genero } & Hombre & 56 & 55.4 \\
\hline & Mujer & 45 & 44.6 \\
\hline & Total & 101 & 100 \\
\hline \multirow[t]{6}{*}{ Civil } & Casado & 20 & 19.8 \\
\hline & Soltero & 72 & 71.3 \\
\hline & Divorciado & 2 & 2 \\
\hline & Viudo & 2 & 2 \\
\hline & Unión Libre & 5 & 5 \\
\hline & Total & 101 & 100 \\
\hline \multirow[t]{5}{*}{ Educación } & Educación Básica & 1 & 1 \\
\hline & $\begin{array}{l}\text { Educación Media } \\
\text { Superior }\end{array}$ & 7 & 6.9 \\
\hline & Educación Superior & 91 & 90.1 \\
\hline & Ninguna & 2 & 2 \\
\hline & Total & 101 & 100 \\
\hline \multirow[t]{7}{*}{ Giro } & Constructora & 40 & 39.6 \\
\hline & Administración & 14 & 13.9 \\
\hline & Diseño & 23 & 22.8 \\
\hline & Vivienda en Serie & 4 & 4 \\
\hline & Desarrollo Urbano & 6 & 5.9 \\
\hline & Empresa Personal & 14 & 12.9 \\
\hline & Total & 101 & 100 \\
\hline \multirow[t]{4}{*}{ Responsabilidad } & Bajo & 10 & 9.9 \\
\hline & Medio & 40 & 39.6 \\
\hline & Alto & 50 & 49.5 \\
\hline & Total & 101 & 100 \\
\hline \multirow[t]{4}{*}{ Modalidad } & A distancia & 19 & 18.8 \\
\hline & $\begin{array}{l}\text { Semi-Presencial } \\
\text { Presencial }\end{array}$ & 39 & 386 \\
\hline & $\begin{array}{l}\text { Presencial con } \\
\text { medidas }\end{array}$ & 43 & 40.6 \\
\hline & Total & 101 & 100 \\
\hline
\end{tabular}

Fuente: Elaboración propia. 
Según los resultados, la reducción con un porcentaje de $54.5 \%$ no bajo, seguida de un $11.9 \%$ bajo un $35 \%$. Sensaciones un $27.7 \%$
Ninguna, 24.8\% Estrés, el Combatir la pandemia en confinamiento fue una parte elemental un $33.7 \%$ lo hacia trabajando.

Tabla 3. Caracterización del estrés emocional de las personas entrevistadas

\begin{tabular}{|c|c|c|c|}
\hline Variable & & Frecuencia & Porcentaje \\
\hline \multirow[t]{8}{*}{ Reducción } & $5 \%$ o menos & 10 & 9.9 \\
\hline & $10 \%$ & 8 & 7.9 \\
\hline & $15 \%$ & 6 & 5.9 \\
\hline & $20 \%$ & 5 & 5 \\
\hline & $35 \%$ & 12 & 11.9 \\
\hline & No, bajo & 55 & 54.5 \\
\hline & Total & 96 & 95 \\
\hline & No aplica & 5 & 5 \\
\hline \multirow[t]{9}{*}{ Sensaciones } & Estrés & 25 & 24.8 \\
\hline & Ansiedad & 14 & 13.9 \\
\hline & Irritabilidad & 6 & 5.9 \\
\hline & Cansancio & 8 & 7.9 \\
\hline & Soledad & 12 & 11.9 \\
\hline & Depresión & 6 & 5.9 \\
\hline & Ninguna & 28 & 27.7 \\
\hline & Total & 99 & 98 \\
\hline & No aplica & 2 & 2 \\
\hline \multirow[t]{8}{*}{ Contagio } & Si tuve contagio & 14 & 13.9 \\
\hline & No tuve contagio & 57 & 56.4 \\
\hline & Tuve síntomas & 15 & 14.9 \\
\hline & leves & 9 & 8.9 \\
\hline & No, tuve contagio & 3 & 3 \\
\hline & $\mathrm{Si}$, tuve contagio & 98 & 97 \\
\hline & Total & 3 & 3 \\
\hline & No aplica & & \\
\hline \multirow[t]{7}{*}{ Desempleo } & & 9 & 8.9 \\
\hline & Despido & 9 & 8.9 \\
\hline & Renuncie & 5 & 5 \\
\hline & Emprendí & 75 & 74.3 \\
\hline & Ninguna & 98 & 97 \\
\hline & Total & 3 & 3 \\
\hline & No aplica & & \\
\hline \multirow[t]{6}{*}{ Combatir } & & 30 & 29.7 \\
\hline & No pensar en eso & 34 & 33.7 \\
\hline & Trabajando & 18 & 17.8 \\
\hline & Descansando & 19 & 18.8 \\
\hline & Ejercitándome & 101 & 100 \\
\hline & Total & & \\
\hline
\end{tabular}

Fuente: Elaboración propia. 
Según los resultados, El giro y la reducción con 6 , la mediana con un 6 correspondiente a reducción salarial seguida de un 4 sensaciones y por ultimo la desviación con un 2.422 correspondiente a sensaciones. Tabla 4 "Estadísticos descriptivos ."

Tabla 4. Estadisticos descriptivos

\begin{tabular}{lcllc}
\hline \multicolumn{1}{c}{ Variable } & Mínimo & Máximo & Mediana & Desviación \\
\hline Edad & 18 & 58 & N/A & 7.890 \\
Genero & 1 & 2 & 1 & .500 \\
Civil & 1 & 5 & 2 & .866 \\
Educación & 1 & 4 & 3 & .354 \\
Giro & 1 & 6 & 2 & 1.752 \\
Responsabilidad & 1 & 3 & 2.50 & .667 \\
Modalidad & 1 & 3 & 2 & .750 \\
Reducción & 1 & 6 & 6 & 1.803 \\
Sensaciones & 1 & 7 & 4 & 2.422 \\
Contagio & 1 & 5 & 2 & .931 \\
Desempleo & 1 & 4 & 4 & .997 \\
Combatir & 1 & 4 & 2 & 1.083
\end{tabular}

Fuente: Elaboración Propia

En el gráfico que a continuation se describe, los participantes señalaron que en mayor medida, no sintierón ninguna sensacion. seguida del estrés el cual tambien fue muy reportado por los entrevistados. La ansiedad y la soledad tambien presentaron numeros elevados.

Figura 1. Gráfico sensaciones

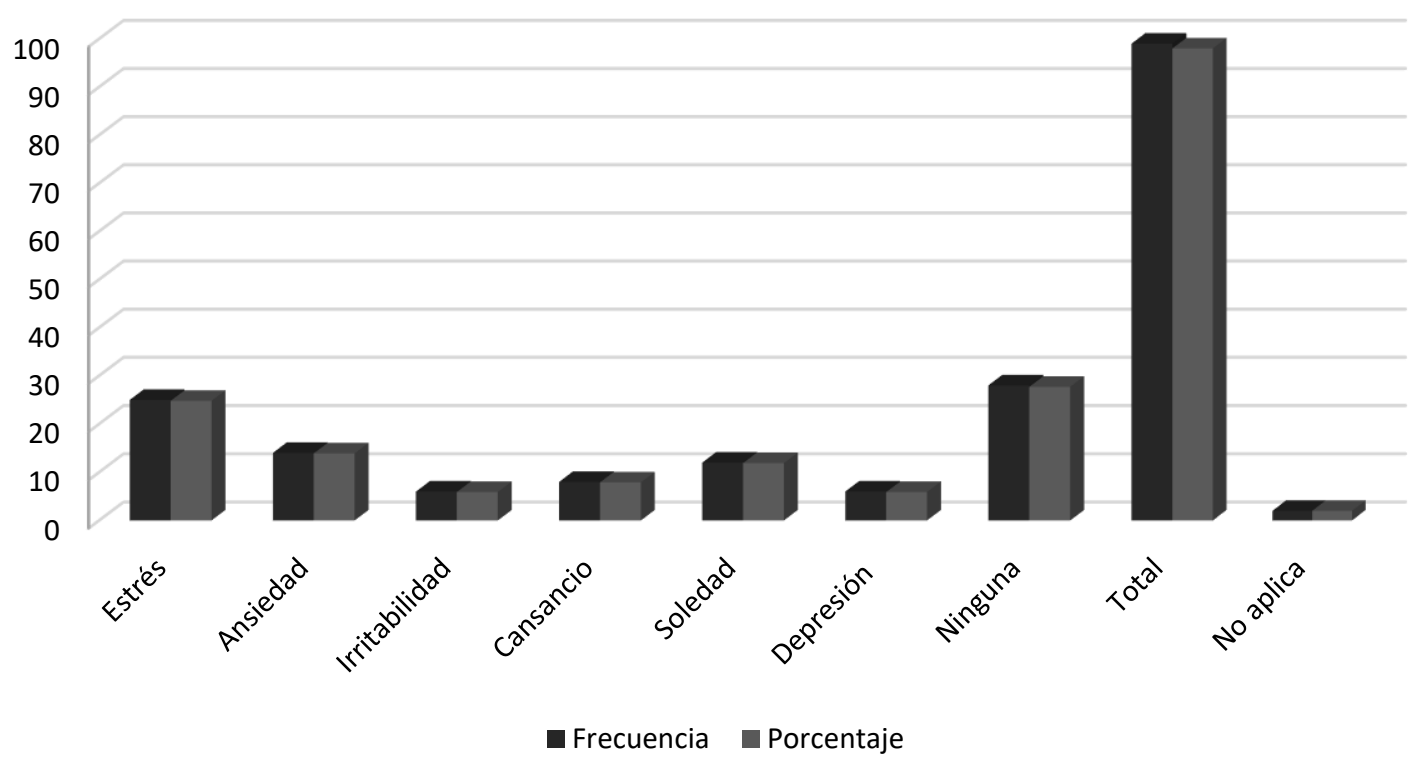

Fuente: Elaboración Propia

La grafica figura 3 (grafico contagio) muestra que en mayor medida los entrevistados "No tuvieron contagio" seguida de "tuve síntomas leves." En la figura 4 
(gráfico combatir) muestra que los medida de escape para enfrentar la crisis. entrevistados respondieron al trabajo como

Figura 3. Gráfico contagio

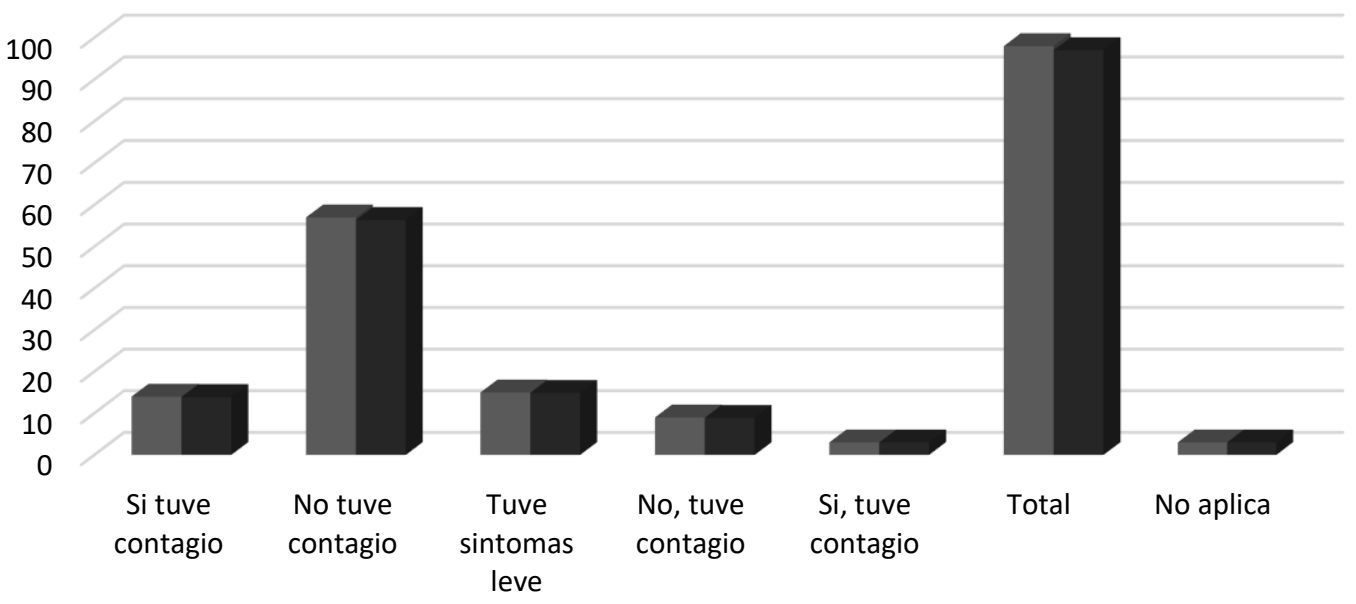

— Frecuencia $\quad$ Porcentaje

Figura 4. Gráfico combatir

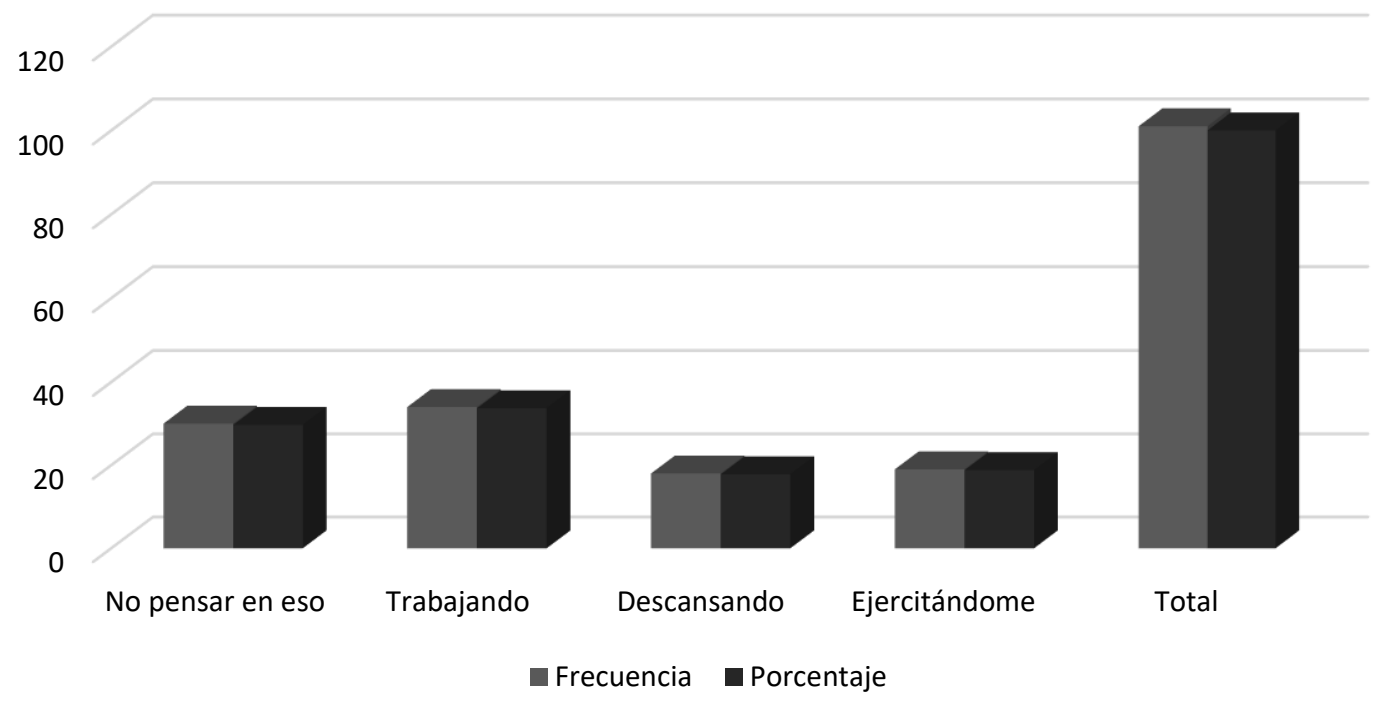

Fuente: Elaboración Propia

\section{CONCLUSIONES}

Se concluyó que las personas durante este confinamiento presentaron Sensaciones en su mayoría de un $(27.7 \%)$ de ningún tipo, seguidas de Estrés (24.8\%), Ansiedad (13.9\%) y soledad con (11.9\%).

Las personas en su mayoría presentaron algún síntoma psicológico entre el
Estrés con mayor porcentaje, seguido de Ansiedad y por último Soledad, pero por otro lado también predominó el grupo de personas que no vivieron ninguna sensación. Por otro lado, en la variable Experiencia, quiere decir que experiencia tuvo al trabajar desde casa y es que la mayoría de los encuestados lo tomaron con positividad y buena experiencia. 
En su mayoría lo que hacían para distraerse y dispersar su mente era no pensar en eso y trabajar y es que en su mayoría trabajando dejaban de pensar en la crisis sanitaria derivada del COVID-19. 


\section{REFERENCIAS:}

Gobierno de Nuevo León. (Mayo 2020). Plan de Reactivación Social y Económica de Nuevo León. 2021, de Gobierno de Nuevo León Sitio web: https://www.nl.gob.mx/publicaciones/presentacion-del-plan-de-reactivacion-economica-ysocial-de-nuevo-leon-ante-covid-19

Gobierno del Estado de Nuevo León. (Marzo 2020). Casos de COVID-19 en Nuevo León. Mayo 2021, de Pagina del Gobierno de Nuevo León Sitio web: www.nl.gob.mx

Inegi. (2020). Número de habitantes. 2021, de Inegi Sitio web: http://cuentame.inegi.org.mx

Secretaria de Infraestructura. (2021). Padrón de empresas contratadas en la secretaria. 2021, de Gobierno de Nuevo León Sitio web: http://si.nl.gob.mx/padron

Marisa Salanova, Esther García y Laura Lorente. (Diciembre del 2007). Riesgos Psicosociales en Trabajadores de la Construcción . 2021, de Equipo WONT prevención psicosocial Universitat, Jaume I. Sitio web: http://www.want.uji.es/wpcontent/uploads/2017/03/2007_Salanova-Gracia-Lorente.pdf

Secretaria de Economía y Trabajo. (Mayo 2020). Impacto económico en Nuevo León ante COVID19. 2021, de Gobierno de Nuevo León Sitio web: https://www.nl.gob.mx/publicaciones/impactoeconomico-en-nuevo-leon-ante-covid-19

Secretaria del Trabajo y Previsión Social . (Julio 2012). Prácticas Seguras en la Industria de la Construcción. 2021, de STPS Gobierno de México Sitio web: http://www.stps.gob.mx/bp/secciones/dgsst/publicaciones/prac_seg/construccion/metodolo gia.pdf

Veronika Sieglin y María Elena Ramos Tovar. (Septiembre 2007). Estrés laboral y depresión entre maestros del área metropolitana de Monterrey. 2021, de Revista mexicana de sociología Sitio web: http://www.scielo.org.mx/scielo.php?script=sci_arttext\&pid=S018825032007000300005

Yris Yessenia Usma Flórez. (Noviembre,2020). El estrés laboral y su incremento durante el confinamiento. Abril, 2021, de Universidad Cooperativa de Colombia Sitio web: https://repository.ucc.edu.co/bitstream/20.500.12494/28446/2/2020_estres_laboral.pdf

Yordany Arias Molina. (Mayo 2020). Manifestaciones psicológicas frente a la situación epidemiológica causada por la COVID-19. Abril 2021, de Universidad de Ciencias Médicas de la Habana Sitio web: http://scielo.sld.cu/scielo.php?script=sci arttext\&pid=S1729519X2020000400012 